\title{
JNPH
}

Volume 6 No. 1 (April 2018)

(C) The Author(s) 2018

\section{FAKTOR-FAKTOR KEAKTIFAN KADER DALAM KEGIATAN POSYANDU DI WILAYAH KERJA PUSKESMAS BETUNGAN KOTA BENGKULU}

\section{THE FACTORS ACTIVENESS OF THE CADRES IN THE INTEGRATED HEALTH CENTER (IHC) ACTIVITIES IN BETUNGAN HEALTH CENTER IN BENGKULU CITY}

\author{
IDA ROYANI \\ UPTD PUSKESMAS PERAWATAN BETUNGAN KOTA BENGKULU \\ JLN. DEPATI PAYUNG NEGARA KM 16,5 KELURAHAN BETUNGAN KECAMATAN \\ SELEBAR KOTA BENGKULU. 38214 \\ Email: royaniida345@gmail.com
}

\begin{abstract}
ABSTRAK
Posyandu adalah pos pelayanan masyarakat, yang merupakan salah satu upaya kesehatan berbasis masyarakat yang dikelola dan diorganisir dari, oleh, untuk dan dengan masyarakat, penurunan menjadi kader yang tidak aktif dalam kegiatan Posyandu dapat menyebabkan ketidakefektifan layanan. Tujuan penelitian ini adalah untuk mengetahui faktor-faktor yang berhubungan dengan keaktifan kader di Posyandu Puskesmas Betungan di Kota Bengkulu pada tahun 2017. Desain penelitian yang digunakan adalah analitik observasional dengan pendekatan cross sectional, penelitian ini dilakukan di Puskesmas Betungan Bengkulu pada 11 Maret - 11 Juni 2017. Populasi penelitian adalah seluruh kader di Puskesmas Betungan Bengkulu, dengan sampel 49 orang diambil dengan menggunakan teknik total sampling. Pengumpulan data dilakukan secara langsung menggunakan lembar daftar periksa, dan dianalisis menggunakan uji chi-square untuk pendidikan dan tes fisher yang dipergunakan dalam variabel umur dan pekerjaan. Hasilnya menunjukkan hampir semua $(87,8)$ usia $25-54$, mayoritas $(73,5)$ kurang berpendidikan, hampir semua $(87,8)$ tidak bekerja dan hampir semua $(87,8)$ adalah kader aktif. Hasil nilai chi-square usia $(\mathrm{p}=0,01)$, pendidikan $(\mathrm{p}=0,00)$ dan pekerjaan $(\mathrm{p}=1.000)$. dengan tingkat $95 \%$, jika $\mathrm{p}<0,05$ berarti ada hubungan antara usia dan pendidikan, dan jika penelitian ini $p>0,05$ berarti tidak ada hubungan antara kerja dengan keaktifan kader di Puskesmas Betungan di Bengkulu. penelitian diharapkan dapat memberikan informasi tentang faktor-faktor yang terkait dengan keaktifan kader dalam kegiatan Posyandu terhadap lembaga-lembaga klinik, kader dan peneliti.
\end{abstract}

Kata Kunci : Keaktifan Kader, Posyandu

\begin{abstract}
IHC is a community service post, which is one of the community-based health effort managed and organized from, by, for and with the community, the decline becomes inactive cadres in IHC activities may lead to the ineffectiveness of service. The purpose of this study was to determine the factors associated with the activeness of cadres in the IHC of Betungan Health Center in the city of Bengkulu in 2017. The design study used was an observational analytic cross sectional approach, this study was conducted in Betungan health center in Bengkulu on
\end{abstract}


March 11 to June 11, 2017. The study population were all cadres in Betungan health center Bengkulu, with the samples of 49 people taken by using a total sampling technique. The collection of data was done directly using the check list sheet, and analyzed using the chisquare test for the education and exacted fisher test used in the variable age and occupation. The results showed nearly all (87.8) aged $25-54$, the majority (73.5) were less educated, almost all (87.8) did not work and almost all (87.8) were active cadres. The results of chi-square value of age $(p=0.01)$, education $(p=0.00)$ and work $(p=1.000)$. with the rate of $95 \%$, if $p<0.05$ means that there was a relationship between age and education, and if this study $p>0.05$ means that there was no relationship between the work with the cadres activeness in Betungan health center in Bengkulu. This study is expected to provide information about the factors associated with the activeness of the cadres in IHC activities to institutions of the clinic, cadres and researchers.

\section{Keywords: Cadre Activity, Posyandu}

\section{PENDAHULUAN}

Posyandu merupakan salah satu Upaya Kesehatan Berbasis Masyarakat (UKBM) yang dikelola dan diselenggarakan dari, oleh, untuk dan bersama masyarakat dalam penyelenggaraan pembangunan kesehatan guna memperdayakan masyarakat dan memberikan kemudahan kepada masyarakat dalam memperoleh pelayanan kesehatan dasar/sosial dasar untuk mempercepat Betungan Kota Bengkulu Angka Kematian Ibu dan Bayi (Depkes RI, 2015). Posyandu yang terintegritas adalah kegiatan pelayanan sosial dasar keluarga dan aspek tubuh kembang anak. Dalam pelaksanaan dilakukan secara koordinatif dan integratif serta saling memperkuat untuk kelangsungan pelayanan di Posyandu sesuai dengan kondisi dan situasi/kondisi kebutuhan lokal yang dalam kegiatannya tetap memperhatikan aspek pemberdayakan masyarakat (Kementerian Kesehatan RI, 2015).

Beberapa faktor dapat dikatakan faktor intrinsik dan ekstrinsik yang berhubungan dengan keaktifan kader diantaranya adalah umur, pendidikan, pekerjaan dan status ekonomi. Faktor ekstrinstik berupa keikutsertaan kader dalam kegiatan bermasyarakat, otoritas kader dalam posyandu yang berupa kebebasan menjalankan tugas pokok kader (Widodo, 2014).

Berdasarkan survei tanggal 29 januari 2017, Berdasarkan Data Dinas Kesehatan
Kota Bengkulu terdapat 20 Puskesmas salah satunya Puskesmas Betungan Kota Bengkulu dengan 10 Posyandu. Pada tahun 2013 jumlah kader 44 kader, pada tahun 2014 sebanyak 45 kader, untuk tahun 2015 dan tahun 2016 jumlah kader 49 kader yang terdiri dari 28 kader aktif dan yang tidak aktif sebesar 21 kader (Dinkes Kota Bengkulu, 2017).

\section{BAHAN DAN METODE}

Desain penelitian yang digunakan secara observasi analitik dengan pendekatan Cross sectional yang suatu penelitian untuk mengetahui hubungan antara variabel antara independent dengan variabel dependent yang dilakukan dalam waktu bersamaan Teknik pengumpulan data yang digunakan dalam penelitian ini adalah dengan menggunakan data primer dan data sekunder. Data primer adalah data yang dikumpulkan melaui responden dengn menggunakan lembar check. Sedangkan data sekunder adalah data yang diperoleh melalui laporan, register pada Puskesmas Betungan Kota Bengkulu Bengkulu tentang jumlah kader pada tahun 2017.

\section{HASIL}

UPTD Puskesmas Betungan Kota Bengkulu terletak di wilayah Betungan Kota Bengkulu yang merupakan salah satu dari Puskesmas yang memiliki dua Puskesmas induk yang berada di wilayah Kecamatan 
Ratu Samban Kota Bengkulu dengan wilayah kerja 4 kelurahan.

Adapun visi dan misi, visinya adalah "Pusat pelayanan kesehatan terdepan, bermutu dan berwawasan pariwisata, menuju kota Bengkulu Sehat Mandiri. Sedangkan misi yang dijalankan adalah menyelenggarakan kemandirian masyarakat untuk berprilaku hidup sehat, menungkatkan kualitas pelayanan yang bermutu dan berstandar serta terjangkau bagi masyarakat, meningkatkan sistem informasi cepat dan akurat dan menjalin kemitraan lintas sektor demi mewujudkan derajat kesehatan masyarakat. Berdasarkan observasi di Puskesmas Betungan Kota Bengkulu Bengkulu terdapat 10 Posyandu dengan jumlah 49 kader. Data yang diperoleh dimasukkan kedalam format pengumpulan data, selanjutnya data di klasifikasikan sesuai dengan masing-masing variabel, yang selanjutnya diberi kode dan dianalisis dengan menggunakan analisa univariat dan analisa bivariat.

Tabel 1 Distribusi Frekuensi Kader Menurut Umur, Pendidikan, Status Pekerjaan di Wilayah kerja Puskesmas Betungan Kota Bengkulu

\begin{tabular}{ccc}
\hline Umur & Frekuensi & $\begin{array}{c}\text { Persentase } \\
\mathbf{( \% )}\end{array}$ \\
\hline $25-54$ & 43 & 87.8 \\
\hline$>54$ & 6 & 12.2 \\
\hline Total & 49 & 100.0 \\
\hline Pendidikan & Frekuensi & $\begin{array}{c}\text { Persentase } \\
\mathbf{( \% )}\end{array}$ \\
\hline Rendah & 36 & 73.5 \\
\hline Menengah & 10 & 20.1 \\
\hline Tinggi & 3 & 6.1 \\
\hline Total & 49 & 100.0 \\
\hline Pekerjaan & Frekuensi & $\begin{array}{c}\text { Persentase } \\
\mathbf{( \% )}\end{array}$ \\
\hline Tidak Bekerja & 43 & 87.8 \\
\hline Bekerja & 6 & 12.2 \\
\hline Total & 49 & 100.0 \\
\hline Keaktifan & Frekuensi & Persentase \\
Kader & & $(\mathbf{\% )}$ \\
\hline Aktif & 43 & 87.8 \\
\hline Tidak aktif & 6 & 12.2 \\
\hline
\end{tabular}

\begin{tabular}{ccc}
\hline Total & 49 & 100.0 \\
\hline
\end{tabular}

Berdasarkan tabel 1 di atas dapat diketahui bahwa hampir seluruh responden $(87,8)$ berumur 25-54, sebagian besar responden $(73,5)$ berpendidikan rendah, hampir seluruh reponden $(87,8)$ tidak bekerja dan hampir seluruh responden $(87,8)$ kader aktif.

Tabel 2 Hubungan Antara Umur dengan Keaktifan Kader dalam Kegiatan Posyandu di wilayah kerja Puskesmas Betungan Kota Bengkulu

\begin{tabular}{cccccccccc}
\hline & & \multicolumn{2}{c}{ Aktif } & \multicolumn{4}{c}{ Tidak Aktif } & Total & \\
\cline { 3 - 8 } No & Umur & $\mathbf{f}$ & $\mathbf{\%}$ & $\mathbf{f}$ & $\mathbf{\%}$ & $\mathbf{f ~}$ & $\mathbf{p}$ & $\begin{array}{c}\text { p- } \\
\text { value }\end{array}$ \\
\hline 1 & $25-54$ & 41 & 95,3 & 2 & 33,3 & 43 & 100 & 0,001 \\
2 & $>54$ & 2 & 4,7 & 4 & 66,7 & 6 & 100 & 0,001 \\
\hline & Total & 43 & & 6 & & 49 & 100 & \\
\hline
\end{tabular}

Berdasarkan hasil analisis data pada tabel di atas, dari 43 responden yang berumur $25-54$ ada $41(95,3 \%)$ yang aktif sedangkan 6 responden yang berusia $(66,7 \%)$ yang tidak aktif. Hasil uji Fisher's Exact test nilai $p$ value $0.001<0.05$ disimpulkan Ho ditolak Ha diterima yang artinya ada hubungan yang bermakna antara umur kader dengan keaktifan kader dengan keaktifan kader dalam posyandu di Puskesmas Betungan Kota Bengkulu.

Tabel 3 Hubungan Antara Pendidikan dengan Keaktifan Kader dalam Kegiatan Posyandu di wilayah kerja Puskesmas Betungan Kota Bengkulu

\begin{tabular}{ccccccccc}
\hline $\begin{array}{c}\text { No Pendidi } \\
\text {-kan }\end{array}$ & Aktif & \multicolumn{3}{c}{ Tidak Aktif } & Total & \\
\hline & & f & \% & f & \% & F & $\%$ & $\boldsymbol{p}$ \\
\hline 1 & Rendah & 33 & 76,7 & 3 & 50,0 & 36100 & \\
2 & Sedang & 10 & 23,3 & 0 & 0 & 10100 & 0,000 \\
3 & Tinggi & 0 & 0 & 3 & 50,0 & 3 & 100 & \\
\hline & Total & 43 & & 6 & & 49 & 100 & \\
\hline
\end{tabular}

Berdasarkan hasil analisis data pada tabel di atas, dari 36 responden yang bependidikan rendah ada $33(76,7 \%)$ yang 
aktif sedangkan 10 responden yang berpendidikan sedang $(23,3 \%)$ yang tidak aktif. Hasil Uji statistik Chi Square test di dapatkan nilai $P=0.000$ lebih kecil dari a (0.05) menunjukkan Ho ditolak Ha diterima yang berarti ada hubungan yang bermakna antara pendidikan kader dengan keaktifan kader dengan keaktifan kader dalam posyandu di Puskesmas Betungan Kota Bengkulu.

Tabel 4 Hubungan Antara Status Pekerjaaan dengan Keaktifan Kader dalam Kegiatan Posyandu di wilayah kerja Puskesmas Betungan Kota Bengkulu.

\begin{tabular}{|c|c|c|c|c|c|c|c|}
\hline \multirow[t]{2}{*}{ No } & \multirow[t]{2}{*}{$\begin{array}{c}\text { Status } \\
\text { Pekerja- } \\
\text { an }\end{array}$} & \multicolumn{2}{|c|}{ Aktif } & \multicolumn{2}{|l|}{$\begin{array}{l}\text { Tidak } \\
\text { aktif }\end{array}$} & \multirow[t]{2}{*}{$\begin{array}{c}\text { Total } \\
\text { f\% }\end{array}$} & \multirow[t]{2}{*}{$p$} \\
\hline & & f & $\%$ & f & $\%$ & & \\
\hline 1 & $\begin{array}{c}\text { Tidak } \\
\text { bekerja }\end{array}$ & 37 & 86,0 & 6 & 5,3 & 43100 & 0,436 \\
\hline \multirow[t]{2}{*}{2} & Bekerja & 6 & 14,0 & 0 & 0 & 6100 & \\
\hline & Total & 43 & & 6 & & 49100 & \\
\hline
\end{tabular}

Berdasarkan hasil analisis data pada tabel di atas, dari 43 responden yang tidak bekerja ada $37(86,0 \%)$ yang aktif sedangkan 6 responden yang bekerja $(14,0 \%)$ yang tidak aktif. Hasil analisa uji Fisher's Exact di dapatkan nilai $\mathrm{p}$ lebih besar dari 0.05 (nilai $p$ value $1,000>0,05$ ) disimpullkan Ho diterima Ha ditolak yang artinya tidak ada hubungan yang bermakna antara pekerjaan kader dengan keaktifan kader dengan keaktifan kader dalam posyandu di Puskesmas Betungan Kota Bengkulu.

\section{PEMBAHASAN}

Berdasarkan hasil penelitian diketahui bahwa hampir seluruh responden berumur 2554 tahun $(87,8 \%)$ aktif, sebagian responden $(73,5 \%)$ pendidikan rendah sesuai dengan teori, dimana penelitian ini termasuk faktor yang berhubungan dengan keaktifan kader, Berdasarkan hasil penelitian diketahui bahwa hampir sebagian reponden berkerja $(87,8 \%)$ aktif. Berdasarkan penelitian diketahui 43 responden yang berumur 25-54 ada 41
$(95,3 \%)$ yang aktif sedangkan 6 responden yang berusia $(66,7 \%)$ yang tidak aktif, Hasil uji Fisher's Exact test nilai $p$ value $0.001<$ 0.05 disimpulkan Ho ditolak Ha diterima yang artinya ada hubungan yang bermakna antara umur kader dengan keaktifan kader dengan keaktifan kader dalam posyandu di Puskesmas Betungan Kota Bengkulu Tahun 2016. Berdasarkan hasil penelitian diketahui 36 responden yang bependidikan rendah ada $33(76,7 \%)$ yang aktif sedangkan 10 responden yang berpendidikan sedang $(23,3 \%)$ yang tidak aktif, dengan menggunakan komputer program SPSS dengan tingkat kepercayaan $95 \%$. Hasil Uji statistik Chi Square test di dapatkan nilai $P=$ 0.000 lebih kecil dari a (0.05) menunjukkan Ho ditolak Ha diterima yang berarti ada hubungan yang bermakna antara pendidikan kader dengan keaktifan kader dengan keaktifan kader dalam posyandu di Puskesmas Betungan Kota Bengkulu Tahun 2016.Berdasarkan hasil penelitian diketahui 43 responden yang tidak bekerja ada 37 $(86,0 \%)$ yang aktif sedangkan 6 responden yang bekerja $(14,0 \%)$ yang tidak aktif, Hasil analisa uji Fisher's Exact di dapatkan nilai p lebih besar dari 0.05 (nilai $p$ value 1,000>0,05) disimpullkan Ho diterima $\mathrm{Ha}$ ditolak yang artinya tidak ada hubungan yang bermakna antara pekerjaan kader dengan keaktifan kader dengan keaktifan kader dalam posyandu di Puskesmas Betungan Kota Bengkulu.

\section{KESIMPULAN}

Dari penelitian yang dilakukan mengenai Faktor-Faktor yang berhubungan dengan Keaktifan Kader dalam kegiatan Posyandu di wilayah Kerja Puskesmas Betungan Kota Bengkulu Bengkulu tahun 2016 dapat disimpulkan bahwa :

1. Hampir seluruh kader berusia 25-54 tahun, sebagian besar kader berpendidikan SLTA, hampir seluruh dari kader tidak bekerja, hampir seluruh kader aktif dalam kegiatan posyandu. 
2. Ada hubungan antara umur dengan keaktifan kader dalam kegiatan posyandu.

3. Ada hubungan antara Pendidikan dengan keaktifan kader dalam kegiatan posyandu.

4. Tidak ada hubungan antara Status Pekerjaan dengan keaktifan kader dalam kegiatan posyandu.

\section{SARAN}

1. Bagi institusi

Penelitian ini diharapkan

memberitahu faktor-faktor yang berhubungan dengan keaktifan kader kepada pihak institusi sehingga diketahui kegiatan yang berperan pada keaktifan kader dalam kegiatan posyandu.

\section{Bagi Puskesmas}

Penelitian ini diharapkan memberikan informasi kepada pihak Puskesmas mengenai beberapa faktor yang berhubungan dengan keaktifan kader dalam kegiatan posyandu yang dapat digunakan sebagai tambahan informasi dalam usaha-usaha mengantisipasi kejadian kurang aktifnya kader dalam kegiatan Posyandu.

\section{Bagi Kader}

Penelitian ini diharapkan memberikan informasi berbagai informasi kepada kader yang aktif dan kurang aktif dalam kegiatan posyandu agar dapat mengatisipasi kesehatan lebih dahulu dan lengkap atau Ikut berperan secara nyata dalam tumbuh kembang anak balita dan kesehatan ibu dan mengantisipasi penyebab kurang aktif para kader.

\section{Bagi Peneliti}

Penelitian ini diharapkan memberikan masukan dan penambahan pengetahuan kepada peneliti tentang program Posyandu.

\section{DAFTAR PUSTAKA}

Cahyo Ismawati Sulistyorini, Sandra Pebriyanti, dan Atikah Proverawati. 2010. "Posyandu dan Desa Siaga", Jakarta: Nuha Medika

Dinas kesehatan kota Bengkulu, 2017. Data Jumlah kader posyandu yang 2014,2015,2016 di puseksmas, Bengkulu

Depkes, 2017. Pedoman Kegiatan Kader di Posyandu, Jakarta.

Fitria, 2014. Tanggapan kader terhadap kunjungan masyarakat di posyandu serta faktor-faktor yang berhubungan di uskesmas Jatimulya Kecamatan Tambun Selatan Kabupaten Bekasi.

Hapsari, 2015. "Faktor-Faktor Yang Berhubungan Dengan Keaktifan Kader Posyandu di Wilayah Kerja Puskesmas Slawi".

http://www.artikelilmiah

Kemenkes RI, 2017. Buku Panduan Kader Posyandu,Jakarta

Mardaniar, 2014. Proposal penelitian. Bengkulu : Stikes Dehasen

Natalia Erlina Yuni dan Rika Sertiana Oktami, 2014. Panduan Lengkap Posyandu untuk bidan dan kader, Yokyakarta :Nuha medika

Notoatmodjo.S, 2010. Metedologi penelitian ilmu keperawatan. Selemba Medika. Jakarta

Nurmaya Setya. 2015. Faktor-faktor yang berhubungan dengan keaktifan kader pada poskesdes dalam program desa siaga di Kecamatan Petarukan Kabupaten Pemalang.

Suhat Ruyatul Hasanah, 2014. "Faktor-Faktor Yang Berhubungan Dengan Keaktifan Kader Dalam Kegiatan Posyandu Di Puskesmas Palasari Kabupaten Subang", $\quad$ http://journal.unnes.ac.id/ nju/indeks.php/kesmas

Skripsi, Fakultas Kesehatan, 2014. Faktorfaktor yang berhubungan dengan keaktifan kader dalam kegiatan Posyandu di Puskesmas Margorejo kabupaten Pati 
http//eprints.dinus.ac.id/7296

Wirapuspita R, 2013. Intensif dan Kinerja

Kader Posyandu. Jurnal Kesmas

http://journal.unnes.ac.id/

nju/indeks.php/kesmas 